\title{
Digestibilidade do grão de trigo de duplo propósito, cultivar BRS Tarumã, produzido em sistema agroecológico ou convencional para suínos $^{1}$
}

\section{Digestibility of wheat grain dual purpose, BRS Tarumã cultivar, produced in agroecological or conventional system for pigs}

\author{
Diovani Paiano ${ }^{2 *}$; Clariana Leon Nantes ${ }^{3}$; Gustavo Krahl' ${ }^{4}$ Jiovani Sergio Bee Tubin ${ }^{5}$; \\ Renato Augusto Conte ${ }^{5}$ João Carlos Dal Pivo ${ }^{5}$ S Sandra Maria Ferraz ${ }^{6}$; Dilmar Baretta ${ }^{7}$
}

\section{Resumo}

Foram conduzidos três ensaios de digestibilidade para determinar o valor nutricional, os coeficientes de digestibilidade aparente e os teores de energia do trigo de duplo propósito (cultivar BRS Tarumã), produzido em sistema agroecológico ou convencional, para suínos em diferentes fases da criação (15, 45 e $75 \mathrm{~kg}$ de peso vivo-PV). Foram utilizados 15 suínos machos castrados, híbridos comerciais de alto desempenho para cada fase, divididos em três grupos experimentais, o primeiro recebeu uma ração específica para a fase, denominada de ração referência (RR), os demais grupos receberam uma ração experimental com $70 \%$ de RR e 30\% de trigo de duplo propósito dos sistemas agroecológico (Grupo 2) ou convencional (Grupo 3). Foram testadas diferenças entre os coeficientes para cada fase do estudo. Para as diferenças entre as fases foram realizadas análises descritivas das médias. Os sistemas de produção (convencional ou agroecológico) não alteraram os coeficientes de digestibilidade do trigo. As médias dos coeficientes de digestibilidade aos 45 e $75 \mathrm{~kg}$ foram maiores. Os valores de energia digestível foram de 3,25; 3,56 e 3,59 Mcal/kg para o trigo convencional e 3,14; 3,45 e 3,57 Mcal/kg para o trigo agroecológico, para as fases de 15, 45 e $75 \mathrm{~kg}$ de PV, respectivamente. A utilização do trigo a partir da fase de $45 \mathrm{~kg}$ apresentou melhores valores de digestibilidade, independente do sistema de produção.

Palavras-chave: Cultura de inverno, digestibilidade, não-ruminantes

\footnotetext{
Abstract

Three experiments of the digestibility were carried out to determine the nutritional value, apparent digestibility and metabolizable coefficients and energy values for dual purpose wheat (BRS Tarumã) produced in agroecological or conventional system, for pigs in different stages $(15,45$ and $75 \mathrm{~kg}$ of body weight -BW). Were used 15 barrows crossbreed of the commercial high-performance hybrids for each

${ }^{1}$ Parte das dissertações do segundo e terceiro autores, Universidade Estadual de Mato Grosso do Sul, PPGZ/UEMS e do Programa de Pós-Graduação em Ciência Animal, CAV/UDESC

${ }^{2}$ Prof. do Dept ${ }^{0}$ de Zootecnia, UDESC, DZO/UDESC, PPGZ/UEMS, Chapecó, SC. E-mail: diovani@hotmail.com

${ }^{3}$ Discente do Curso de Mestrado em Zootecnia, PPGZ/UEMS, Bolsista CAPES, Aquidauana, MS. E-mail: clari_nantes@ hotmail.com

${ }^{4}$ Discente do Curso de Mestrado em Ciência Animal, CAV/UDESC, Bolsista CAPES, Lages, SC. E-mail: gustavo.zootecnista@ live.com

${ }^{5}$ Discentes do Curso de Graduação em Zootecnia, UDESC, Chapecó, SC. E-mail: tubin@live.com; renato_conte@hotmail.com; joaodalpivo@hotmail.com

${ }^{6}$ Prof ${ }^{a}$, CAV/UDESC, Lages, SC. E-mail: sandra.ferraz@udesc.br

${ }^{7}$ Prof., DZO/UDESC, Chapecó, SC. E-mail: dilmar.baretta@udesc.br

* Autor para correspondência
} 
phase, allotted in three experimental groups, the first group received a diet specific to stage, called basal diet (BD) the other groups received diet with $70 \% \mathrm{RR}$ and $30 \%$ of dual-purpose wheat agroecological (Group 2) or conventional (Group 3). Were evaluated differences between the coefficients for each phase of the study. For the differences between phases were used descriptive analyzes. Production systems (conventional and agroecological) not affect the digestibility of wheat. The mean digestibility coefficients at 45 and $75 \mathrm{~kg}$ were higher. The digestible energy values were $3.25,3.56$ and $3.59 \mathrm{Mcal} / \mathrm{kg}$ for conventional and 3.14, 3.45 and $3.57 \mathrm{Mcal} / \mathrm{kg}$ for agroecological wheat for phases 15,45 and $75 \mathrm{~kg}$ of BW, respectively. The use of wheat from the stage $45 \mathrm{~kg}$ showed better digestibility values, regardless of the production system.

Key words: Digestibility, non-ruminants, winter crop

\section{Introdução}

A alimentação representa cerca de $76 \%$ dos custos na produção de suínos (SANTOS et al., 2013), dentre os ingredientes base o milho, por suas características nutricionais e disponibilidade, é o principal alimento energético nas rações de suínos e corresponde em aproximadamente 75\% do volume da ração e cerca de $50 \%$ dos custos do arraçoamento, o que torna os lucros da cadeia de produção de suínos, em especial os suinocultores, dependentes do preço do milho (SILVA et al., 2005; HAUSCHILD et al., 2008).

Por isso, existe interesse por alimentos alternativos que possam reduzir a dependência do milho e do farelo de soja e, por consequência, reduzir o custo das rações sem comprometer o desempenho dos animais (BRITO et al., 2008). Neste sentido, o trigo representa uma boa alternativa como ingrediente para rações em função do seu volume de produção, custo e valor nutricional, o que o torna uma boa estratégia para manutenção dos lucros da suinocultura em regiões com escassez ou irregularidade no fornecimento de milho (FREITAS et al., 2005; MARQUES et al., 2007). Deste modo, destaca-se o trigo de dupla aptidão o qual, além do grão, eventualmente pode ser utilizado para a pastagem como uma ferramenta interessante para o produtor rural, em especial para produtores da região Sul do Brasil (SANTOS et al., 2011b).

De acordo com a CONAB (2013) o Brasil produziu, na safra 2012/13, cerca de 4,4 milhões de toneladas de trigo, com $95 \%$ da produção total na região Sul o que é um bom indicativo do potencial do trigo como alimento alternativo.

Sob o ponto de vista nutricional o trigo apresenta 3,35 Mcal/kg de energia digestível (ED), valor inferior ao milho (3,46 Mcal/kg de ED), em relação ao teor de proteína o trigo apresenta e $11,7 \%$ de PB, superior ao do milho de 7,88\% de PB (ROSTAGNO et al., 2011), o que evidencia seu potencial nutricional, porém, reforça a necessidade de novas avaliações.

Em relação à produção de trigo em sistema agroecológico, Mazzoncini et al. (2007) verificaram que o sistema convencional apresentou grãos com 14,6\% de PB quando comparado ao agroecológico com $11,4 \%$ de $\mathrm{PB}$, assim como maior produtividade por hectare. Todavia, cereais de inverno necessitam de novas avaliações, em relação aos sistemas com integração lavoura pecuária (SANTOS et al., 2011b).

Entretanto, são poucos os trabalhos na literatura nacional que avaliam variedades de trigo de dupla aptidão produzidos em sistemas agroecológicos ou convencional e a sua relação com a nutrição de suínos. Face ao exposto, o presente trabalho foi realizado para determinar o valor nutricional, os coeficientes de digestibilidade e o valor energético dos grãos de trigo de uma variedade de dupla aptidão, denominado comercialmente de trigo de duplo propósito, produzido em sistema agroecológico ou convencional para suínos nas diferentes fases de produção $(15,45$ e $75 \mathrm{~kg}$ de PV). 


\section{Material e Métodos}

Foram conduzidos três ensaios de digestibilidade com suínos nas fases iniciais, crescimento e terminação para determinar o valor nutricional e os coeficientes de digestibilidade aparente do grão de trigo da cultivar BRS Tarumã (Triticum aestivum L.), produzidos no sistema agroecológico ou convencional.

O trigo convencional foi produzido no município de Xanxerê/SC (26 $\left.50^{\circ} \mathrm{S}-52^{\circ} 26^{\prime} \mathrm{W}\right)$, em Latossolo Vermelho distrófico de textura argilosa (EMBRAPA, 1999) e com sistema de plantio direto e integração lavoura pecuária, seguindo as recomendações agronômicas e de adubação de manutenção para a cultura (COMISSÃO DE QUÍMICA E FERTILIDADE DO SOLO, 2004), com base nos resultados de análise do solo. $\mathrm{O}$ trigo agroecológico foi produzido no Centro de Treinamento de Chapecó (CETREC), da Empresa de Pesquisa Agropecuária e Extensão Rural de Santa Catarina (EPAGRI), localizado no Distrito Marechal Bormann, no município de Chapecó/SC $\left(27^{\circ} 11^{\prime} \mathrm{S}-52^{\circ} 39^{\prime} \mathrm{W}\right)$. A cultura foi adubada com $48 \mathrm{~m}^{3} / \mathrm{ha}$ de dejetos de suínos e para combate aos fungos foi utilizado sulfato de cobre, conforme recomendações para o sistema agroecológico. As épocas de semeadura, o controle de plantas daninhas e os tratamentos fitossanitários obedeceram às indicações técnicas da cultura do trigo de acordo com as recomendações e especificidades de cada sistema de produção. A colheita do trigo foi efetuada com colhedeira no sistema convencional e manualmente no sistema agroecológico, não foram avaliados os componentes de produção.

Os experimentos para a avaliação da digestibilidade e do valor nutricional do grão de trigo foram conduzidos nos meses de fevereiro a outubro de 2012, com um ensaio específico para cada fase, no setor de suinocultura da Escola Básica Municipal em Agropecuária Demétrio Baldissarelli, (27 $\left.7^{\circ} 2^{\prime} \mathrm{S}-52^{\circ} 37^{\prime} \mathrm{W}\right)$, localizada no Distrito Marechal Bormann, no município de Chapecó/SC.
Para os ensaios de digestibilidade foram utilizados 15 suínos machos castrados, híbridos comerciais de alto desempenho, com médias de $11,7 \pm 0,8 \mathrm{~kg} ; 42,6 \pm 3,2 \mathrm{~kg}$ e $78,1 \pm 3,1 \mathrm{~kg}$ de PV para as fases iniciais, crescimento e terminação, respectivamente. Em cada fase os animais foram divididos em três grupos experimentais, com cinco animais por grupo, o primeiro grupo recebeu uma ração denominada referência (RR) (Tabela 1), calculada conforme as exigências nutricionais e composição química propostas por Rostagno et al. (2011), o segundo grupo recebeu uma dieta experimental com $70 \%$ de RR $+30 \%$ de inclusão de grãos de trigo de duplo propósito produzidos no sistema agroecológico e o terceiro grupo recebeu uma dieta similar ao grupo 2 mas com $30 \%$ de inclusão de trigo do sistema convencional (Grupo 3).

Os suínos foram alojados individualmente em gaiolas experimentais tipo Pekas (1968). Foram utilizados sete dias de adaptação ao ambiente, rações e manejo alimentar, seguidos de cinco dias de coleta total de excretas. A quantidade diária de ração fornecida no período experimental foi estabelecida com base no consumo por peso metabólico $\left(\mathrm{PV}^{0,75}\right)$, obtido no decorrer da fase de adaptação.

As rações foram fornecidas às $08 \mathrm{~h} 30 \mathrm{~min}$ e às 16h30min, foram umedecidas com aproximadamente $30 \%$ do peso em água, para facilitar o consumo, diminuir os desperdícios e o pó e a água foi oferecida à vontade aos animais após o consumo da ração.

Foi utilizado o método de coleta total de fezes, com a utilização do óxido de ferro $\left(2 \%\right.$ de $\left.\mathrm{Fe}_{3} \mathrm{O}_{2}\right)$ como marcador fecal. O fornecimento das dietas, coleta de fezes e urina foram realizados de acordo com a metodologia preconizada por Sakomura e Rostagno (2007).

A determinação da composição química das rações, do trigo (Tabelas 1 e 2) e fezes foi realizada conforme metodologias preconizadas por Silva e Queiroz (2002). A energia bruta foi determinada conforme metodologia da AOAC (1995), por meio 
do uso de bomba calorimétrica, Modelo IKA C200 ${ }^{\circledR}$, obtido de acordo com a metodologia preconizada programada no modo dinâmico. O teor de amido foi por Brasil (1998).

Tabela 1. Composição das rações referências utilizadas para as fases de 15, 45 e $75 \mathrm{~kg}$ de peso vivo.

\begin{tabular}{|c|c|c|c|}
\hline \multirow{2}{*}{ Itens, $\%$} & \multicolumn{3}{|c|}{ Composição centesimal das rações referências } \\
\hline & $15 \mathrm{~kg}$ & $45 \mathrm{~kg}$ & $75 \mathrm{~kg}$ \\
\hline Milho & 60,72 & 70,44 & 75,60 \\
\hline Farelo de soja & 30,14 & 26,30 & 20,93 \\
\hline Açúcar & 5,00 & - & - \\
\hline Fosfato bicálcico & 1,48 & 1,12 & 0,86 \\
\hline Calcário & 0,74 & 0,65 & 1,32 \\
\hline Óleo de soja & 0,67 & 0,57 & 0,50 \\
\hline Suplemento vitamínico+mineral & 0,50 & 0,30 & 0,15 \\
\hline Sal comum & 0,41 & 0,36 & 0,32 \\
\hline L-Lisina $\mathrm{HCl}$ & 0,30 & 0,23 & 0,28 \\
\hline DL-Metionina & 0,03 & 0,03 & 0,04 \\
\hline L-Treonina & - & - & 0,06 \\
\hline \multicolumn{4}{|l|}{ Composição química e energética } \\
\hline Energia bruta, $\mathrm{Mcal} / \mathrm{kg}^{1}$ & 4,28 & 4,43 & 4,41 \\
\hline Energia metabolizável, Mcal $/ \mathrm{kg}^{2}$ & 3,24 & 3,24 & 3,24 \\
\hline Matéria seca, $\%^{1}$ & 91,24 & 89,20 & 88,87 \\
\hline Matéria orgânica, $\%^{1}$ & 94,75 & 84,91 & 95,87 \\
\hline Cálcio, $\%^{2}$ & 0,74 & 0,61 & 0,79 \\
\hline Fósforo disponível, $\%{ }^{2}$ & 0,38 & 0,31 & 0,26 \\
\hline Sódio, $\%{ }^{2}$ & 0,18 & 0,16 & 0,15 \\
\hline Proteína bruta, $\%^{3}$ & 21,04 & 19,81 & 18,10 \\
\hline Proteína bruta, $\%^{2}$ & 18,97 & 17,97 & 16,05 \\
\hline Lisina, $\%^{2}$ & 1,11 & 0,98 & 0,89 \\
\hline Metionina + cistina, $\%^{2}$ & 0,57 & 0,56 & 0,52 \\
\hline Triptofano, $\%{ }^{2}$ & 0,20 & 0,19 & 0,16 \\
\hline Treonina, $\%{ }^{2}$ & 0,63 & 0,59 & 0,58 \\
\hline Valina, $\%{ }^{2}$ & 0,79 & 0,75 & 0,67 \\
\hline Isoleucina, $\%{ }^{2}$ & 0,72 & 0,67 & 0,58 \\
\hline Arginina, $\%^{2}$ & 1,18 & 1,09 & 0,94 \\
\hline
\end{tabular}

${ }^{1}$ Valores analisados conforme metodologias de Silva e Queiroz (2002); ${ }^{2}$ Valores calculados com base na composição química e coeficientes de digestibilidade propostos por Rostagno et al. (2011); ${ }^{3}$ Valores analisados conforme metodologias preconizada por Tedesco et al. (1995).

Fonte: Elaboração dos autores. 
A composição aminoacídica do trigo foi analisada em cromatografia líquida de alta performance (HPLC), conforme metodologia da AOAC (1995). As análises para a obtenção dos teores de $\mathrm{Ca}, \mathrm{P}$ e $\mathrm{N}$ foram realizadas de acordo com Tedesco et al. (1995).

O teor da micotoxina Desoxinivalenol (DON) nos grãos de trigo foi determinado pela técnica ELISA (Enzyme Linked Immunono Sorbent Assay) direto por competição, por meio do kit analítico Romerlabs, Singapure Pte Ltd.

$\mathrm{O}$ diâmetro geométrico médio (DGM) e o desvio padrão geométrico (DPG) do grão do trigo foram obtidos segundo a metodologia de Henderson e Perry (1955).

Com os valores de matéria seca das rações e fezes e a composição química e energética das rações, trigo, fezes e urina foram calculados os nutrientes digestíveis, e os valores de digestibilidade (MATTERSON et al., 1965; SAKOMURA; ROSTAGNO, 2007). Posteriormente, foram calculados os coeficientes de digestibilidade aparente da matéria seca (CDMS), coeficiente de digestibilidade aparente da proteína bruta (CDPB), coeficiente de digestibilidade aparente da matéria orgânica (CDMO), coeficiente de digestibilidade aparente da energia bruta (CDEB) e coeficiente de metabolização da energia bruta (CMEB) dos alimentos avaliados.
Os coeficientes obtidos, para cada fase, foram submetidos ao teste de normalidade dos erros Shapiro-Wilk $(\mathrm{P}<0,05)$ e submetidos à análise de variância, com base no seguinte modelo estatístico: $\mathrm{Y}_{j k}=\mu+\mathrm{T}_{j}+\mathrm{e}_{j k}$, em que: $\mathrm{Y}_{j k}=$ Valor observado; $\mu=$ constante associada a todas as observações; $\mathrm{T}_{j}=$ efeito da origem do trigo, sendo $j=$ cultivado no sistema convencional ou agroecológico; $\mathrm{e}_{j k}=$ erro aleatório associado à observação, os dados foram analisados por meio do programa SAEG 9.1 (UFV, 2007). Pelo fato dos animais não receberem a mesma dieta referência, a qual foi específica para cada fase (Tabela 1), a comparação de médias entre as fases foi realizada por meio de estatística descritiva.

\section{Resultados e Discussão}

A composição química do grão do trigo (Tabela 2), independente do sistema de produção, foi próxima aos valores encontrados por Thacker e Widyaratne (2007) de 14,2\% de proteína bruta (PB) e 1,4\% de extrato etéreo (EE), da mesma forma, o teor de energia bruta ( $\mathrm{kcal} / \mathrm{kg} \mathrm{MS}$ ) do grão de trigo agroecológico $(4,44 \mathrm{Mcal} / \mathrm{kg})$ e convencional $(4,41 \mathrm{Mcal} / \mathrm{kg})$ foram próximos ao obtido Del Álamo et al. (2008) e Thacker e Widyaratne (2007) de 4,41 e 4,44 Mcal/kg de MS, respectivamente. 
Tabela 2. Composição química e características físicas do trigo de duplo propósito cv. BRS Tarumã, cultivado no sistema convencional ou agroecológico (na matéria natural).

\begin{tabular}{|c|c|c|c|}
\hline Composição química & Convencional & Agroecológico & Médias \\
\hline Matéria seca, $\%^{1}$ & 89,00 & 88,24 & 88,62 \\
\hline Proteína bruta, $\%{ }^{1}$ & 17,74 & 15,05 & 16,40 \\
\hline Amido total, $\%^{3}$ & 56,18 & 57,40 & 56,79 \\
\hline Gordura, $\%^{1}$ & 1,48 & 1,60 & 1,54 \\
\hline Energia bruta, Mcal $/ \mathrm{kg}^{1}$ & 3,92 & 3,86 & 3,89 \\
\hline Fibra em detergente neutro, $\%^{1}$ & 11,25 & 11,08 & 11,17 \\
\hline Fibra em detergente ácido, $\%{ }^{1}$ & 2,83 & 2,78 & 2,81 \\
\hline Hemicelulose, $\%^{1}$ & 8,42 & 8,27 & 8,35 \\
\hline Celulose, $\%^{1}$ & 2,24 & 2,06 & 2,15 \\
\hline Matéria Orgânica, ${ }^{1}$ & 86,44 & 86,19 & 86,32 \\
\hline Matéria Mineral, $\%{ }^{1}$ & 2,56 & 2,05 & 2,31 \\
\hline $\mathrm{Ca}, \%^{2}$ & 0,05 & 0,07 & 0,06 \\
\hline $\mathrm{P}, \%^{2}$ & 0,31 & 0,33 & 0,32 \\
\hline $\mathrm{Mg}, \%^{2}$ & 0,22 & 0,25 & 0,24 \\
\hline $\mathrm{N}, \%{ }^{2}$ & 3,66 & 3,62 & 3,64 \\
\hline $\mathrm{K}, \%{ }^{2}$ & 0,64 & 0,60 & 0,62 \\
\hline $\mathrm{pH}^{2}$ & 5,80 & 5,90 & \\
\hline \multicolumn{4}{|l|}{ Características Físicas } \\
\hline Peso hectolitro, $\mathrm{kg} / \mathrm{hL}$ & 75,89 & 74,16 & \\
\hline Peso de 1000 unidades, g & 24,17 & 24,53 & \\
\hline DGM grão inteiro, $\mu \mathrm{m}^{4}$ & 2974 & 2977 & \\
\hline DPG grão inteiro ${ }^{4}$ & 1,09 & 1,07 & \\
\hline DGM grão moído, $\mu \mathrm{m}^{4}$ & 685 & 673 & \\
\hline DPG grão moído ${ }^{4}$ & 2,25 & 2,07 & \\
\hline $\mathrm{DON}, \mathrm{mg} / \mathrm{kg}^{5}$ & 0,94 & 2,35 & \\
\hline
\end{tabular}

${ }^{1}$ Valores analisados conforme metodologias preconizadas por Silva e Queiroz (2002); ${ }^{2}$ Valores analisados conforme metodologia preconizada por Tedesco et al. (1995); ${ }^{3}$ Valor analisado conforme BRASIL (2005); ${ }^{4}$ DGM (diâmetro geométrico médio) do grão inteiro ou moído; DPG (desvio padrão geométrico) do grão inteiro ou moído conforme metodologia descrita por Henderson e Perry (1955); ${ }^{5} \mathrm{DON}$ (Desoxinivalenol).

Fonte: Elaboração dos autores.

De modo semelhante aos demais nutrientes o teor de amido total do trigo de agroecológico $(57,4 \%)$ e convencional $(56,18 \%)$ foram próximos aos citados por Rostagno et al. (2011) de 54,93\%, no entanto, superior ao obtido por Urynek e Buraczewska (2003) de 47,60\%. Os teores de Ca e $\mathrm{P}$ foram próximos aos valores apresentados por Pedersen, Boersma e Stein (2007) de 0,04 e 0,38\% e de $\mathrm{Ca}$ e $\mathrm{P}$, respectivamente.
Foi verificado uma grande variação na composição química do trigo obtidos por diferentes autores, em que a proteína bruta variou de 10,9\% (DEL ALAMO et al., 2008) à 19,8\% (WIDYARATNE; ZIJLSTRA, 2007), fibra em detergente neutro-FDN de 9,25\% (NUNES et al., 2001) à 18,4\% de (ZIJLSTRA; DE LANGE; PATIENCE, 1999) e a fibra em detergente ácido-FDA 2,65\% (NUNES et al., 2001) à 
4,82\% (NYACHOTI et al., 2005). Isto se deve, provavelmente, as diferentes variedades estudadas ou dos sistemas de produção adotados, apesar de que os valores obtidos para a variedade estudada, nos dois sistemas de produção, foram próximos aos resultados da literatura.

Foram obtidos 2,35 e $0,97 \mathrm{mg} / \mathrm{kg}$ de Desoxinivalenol (DON) no trigo produzido no sistema agroecológico e convencional, respectivamente. A presença de DON esta associada, principalmente, ao ataque pelo fungo Fusarium graminearum Schwabe o qual causa giberela (fusariose) e consequentemente danos à cultura. $O$ crescimento do fungo pode ser favorecido por condições climáticas comuns nas principais regiões produtoras de trigo do Brasil (DEL PONTE et al., 2004; SANTOS et al., 2011a). Em animais, a DON causa recusa de alimento e vômitos, principalmente em suínos (CALORIDOMINGUES et al., 2007).

Resultados similares ao do presente trabalho foram obtidos por Ok et al. (2011) que avaliaram a ocorrência de micotoxinas em diferentes cereais, produzidos nos sistema orgânico ou convencional, e verificaram maior incidência de DON nos cereais produzidos nos sistemas orgânicos do que nos cereais produzidos no sistema convencional. Por outro lado, diferem do trabalho de Schneweis et al. (2005) no qual relatam que o trigo em sistema convencional apresenta mais contaminação por Fusarium e maior concentração de DON que o trigo produzido em sistema orgânico.

De acordo com a ANVISA (2011) o limite máximo tolerável para DON no trigo e subprodutos é de $2,0 \mathrm{mg} / \mathrm{kg}$, entretanto, não foram observados efeitos adversos aos animais durante o período experimental, este resultado pode decorrer pelo fato de que o trigo, nas dietas experimentais, substituiu em $30 \%$ a ração referência, o que diluiu sua concentração e consequentemente os sintomas de intoxicação.

Os teores lisina do trigo agroecológico $(0,400 \%)$ e convencional $(0,419 \%)$ foram superiores aos obtidos por Nyachoti et al. (2005) de $0,34 \%$ e de lisina, provavelmente resultado das características da variedade estudada (Tabela 3). Para os demais aminoácidos os resultados foram próximos aos valores reportados por Rostagno et al. (2011) e NRC (1998).

Os resíduos dos coeficientes de digestibilidade apresentaram distribuição normal $(\mathrm{P}>0,05)$. Não houve efeito $(\mathrm{P}>0,05)$ do sistema de produção, no entanto, foram verificados maiores médias para os coeficientes para os animais nas fases de 45 e 75 $\mathrm{kg}$ (Tabela 4). 
Tabela 3. Composição aminoacídica do trigo de duplo propósito cv. BRS Tarumã, cultivado em Sistema convencional ou Agroecológico (valores na matéria natural).

\begin{tabular}{lccc}
\hline \multicolumn{1}{c}{ Essenciais } & Convencional & Agroecológico totais, ${ }^{1}$ & Médias \\
\hline Lisina & 0,419 & 0,400 & 0,410 \\
Treonina & 0,474 & 0,414 & 0,444 \\
Metionina & 0,234 & 0,206 & 0,220 \\
Metionina+Cistina & 0,557 & 0,505 & 0,531 \\
Valina & 0,689 & 0,610 & 0,650 \\
Histidina & 0,392 & 0,344 & 0,368 \\
Fenilalanina & 0,841 & 0,727 & 0,784 \\
Leucina & 1,134 & 0,985 & 1,060 \\
Isoleucina & 0,551 & 0,506 & 0,529 \\
Arginina & 0,744 & 0,672 & 0,708 \\
\hline \multicolumn{1}{c}{ Não essenciais } & & \\
\hline Alanina & 0,576 & 0,511 & 0,544 \\
Ácido Aspártico & 0,814 & 0,747 & 0,781 \\
Ácido Glutâmico & 5,878 & 4,662 & 5,270 \\
Cistina & 0,323 & 0,299 & 0,311 \\
Glicina & 0,721 & 0,594 & 0,658 \\
Serina & 0,841 & 0,695 & 0,768 \\
Tirosina & 0,537 & 0,478 & 0,508 \\
\hline
\end{tabular}

${ }^{1}$ Valores determinados por cromatografia líquida de alta performance (HPLC) conforme AOAC (1995).

Fonte: Elaboração dos autores.

Tabela 4. Coeficientes de digestibilidade aparente de grãos de trigo produzidos no sistema agroecológico e convencional para suínos $(15,45$ e $75 \mathrm{~kg})$.

\begin{tabular}{|c|c|c|c|c|c|}
\hline & $\mathrm{CDE}^{1}$ & $\mathrm{CME}^{2}$ & $\mathrm{CDMS}^{3}$ & $\mathrm{CDMO}^{4}$ & $\mathrm{CDPB}^{5}$ \\
\hline Pesos vivos, $\mathrm{kg}$ & \multicolumn{5}{|c|}{ Grãos de Trigo cultivado em sistema convencional } \\
\hline 15 & 82,68 & 81,15 & 83,30 & 85,14 & 72,22 \\
\hline 45 & 90,57 & 86,43 & 90,07 & 91,25 & 90,60 \\
\hline \multirow[t]{2}{*}{75} & 91,28 & 87,03 & 88,65 & 89,76 & 92,39 \\
\hline & \multicolumn{5}{|c|}{ Grãos de Trigo cultivado em sistema agroecológico } \\
\hline 15 & 81,15 & 80,61 & 86,73 & 89,69 & 74,43 \\
\hline 45 & 89,34 & 88,27 & 90,05 & 90,47 & 86,78 \\
\hline \multirow[t]{2}{*}{75} & 92,40 & 88,26 & 91,88 & 92,86 & 88,54 \\
\hline & \multicolumn{5}{|c|}{ Médias gerais dos coeficientes de digestibilidade dos trigos } \\
\hline 15 & 81,92 & 80,88 & 85,02 & 87,42 & 73,33 \\
\hline 45 & 89,96 & 87,35 & 90,06 & 90,86 & 88,69 \\
\hline 75 & 91,84 & 87,65 & 90,27 & 91,31 & 90,47 \\
\hline Efeito do sistema na fase de $15 \mathrm{~kg}$ & ns & ns & $\mathrm{ns}$ & ns & $\mathrm{ns}$ \\
\hline Efeito do sistema na fase de $45 \mathrm{~kg}$ & ns & $\mathrm{ns}$ & $\mathrm{ns}$ & $\mathrm{ns}$ & $\mathrm{ns}$ \\
\hline Efeito do sistema na fase de $75 \mathrm{~kg}$ & $\mathrm{~ns}$ & ns & $\mathrm{ns}$ & ns & $\mathrm{ns}$ \\
\hline
\end{tabular}

${ }^{1} \mathrm{CDE}$ - Coeficiente de digestibilidade da energia; ${ }^{2} \mathrm{CME}$ - Coeficiente de metabolização da energia; ${ }^{3} \mathrm{CDMS}-\mathrm{Coeficiente}$ de digestibilidade da matéria seca; ${ }^{4} \mathrm{CDMO}$ - Coeficiente de digestibilidade da matéria orgânica; ${ }^{5} \mathrm{CDPB}$ - Coeficiente de digestibilidade da proteína Bruta.

Fonte: Elaboração dos autores. 
Os resultados semelhantes $(\mathrm{P}>0,05)$ dos coeficientes de digestibilidade, dos grãos de trigo proveniente dos dois sistemas de produção, podem estar associados ao fato das diferenças empregadas nos diferentes sistemas de produção avaliados (convencional ou agroecológico) não serem suficientes para alterar os coeficientes de digestibilidade. Embora, o teor de proteína tenha sido maior no trigo de origem convencional, semelhante aos resultados de Mazzoncini et al. (2007), o teor de amido foi maior no trigo agroecológico. Segundo Zijlstra, De Lange e Patience (1999) o teor de proteína, maior no trigo convencional, tem contribuição positiva com a energia digestível, assim como o teor de amido, maior no trigo agroecológico, o que explicaria a ausência de efeitos sobre os coeficientes de digestibilidade do trigo dos dois sistemas (Tabela 2).

A análise descritiva indicou maior média dos coeficientes de digestibilidade nas fases finais, os quais podem estar associados a fatores como o desenvolvimento do animal e o respectivo desenvolvimento do trato digestório, maior capacidade digestiva e volumétrica, menor taxa de passagem, maior atividade microbiana sobre a fração não digestível entre outros (LE GOFF; VAN MILGEN; NOBLET, 2002).

Outro fator a ser considerado é a presença de fatores antinutricionais que podem diminuir a digestibilidade, principalmente em animais jovens. Segundo Choct (2002), o trigo pode ter até 6,3\% de arabinoxilanas insolúveis e até $1,8 \%$ de solúveis, e até $0,4 \%$ de $\beta$-glucanos solúveis e insolúveis, e quando solúveis podem aumentar a viscosidade da dieta e diminuir a digestibilidade.

Somado ao fator aumento da viscosidade a presença de carboidratos não digeríveis como a rafinose $(4,7 \mathrm{mg} / \mathrm{g})$, pode causar desenvolvimento de micro-organismos indesejáveis no trato digestório, inflamação das mucosas e, por consequência, diarreia, principalmente em leitões recém-desmamados (GRIESHOP; REESE; FAHEY
JÚNIOR, 2001), o que pode ter contribuído com os resultados nas diferentes fases.

Resultados similares aos obtidos para o CDEB, foram reportados por Le Goff, Van Milgen e Noblet (2002) que avaliaram o efeito do nível e origem botânica (milho, farelo de trigo e polpa de beterraba) sobre a digestibilidade da energia e nutrientes no trato digestório de suínos em três fases (crescimento com $35 \mathrm{~kg}$ de $\mathrm{PV}$, terminação com $80 \mathrm{~kg}$ e porcas adultas com $252 \mathrm{~kg}$ ) e verificaram aumento no coeficiente de digestibilidade da energia do farelo de trigo com o aumento do peso dos animais (77,9; 80,8 e 82,5\% do CDEB para os 35,80 e $252 \mathrm{~kg}$ de PV, respectivamente). Os autores relataram que a melhor digestibilidade da fração fibrosa das dietas, com o aumento do peso vivo, está associada ao maior tempo de retenção da digesta, o que provavelmente também contribuiu para os resultados obtidos. Da mesma forma, Noblet e Van Milgen (2004) afirmaram que a digestibilidade da energia é influenciada por fatores inerentes ao animal, como o peso vivo, com melhores resultados para animais maiores.

Para os CDPB, Le Goff, Van Milgen e Noblet (2002) verificaram aumento linear no CDPB do farelo de trigo com o aumento do peso dos suínos (77,2 e 84,3\% de CDPB para as fases de crescimento e terminação, respectivamente), resultados semelhantes aos CDPB do presente trabalho.

O CDMS de 90,01 e $88,65 \%$ para o trigo convencional e 90,05 e $91,88 \%$ para o trigo agroecológico, respectivamente, para a fase de 45 e $75 \mathrm{~kg}$ de $\mathrm{PV}$, foram próximos aos obtido por Nyachoti et al. (2005) para o CDMS do trigo de $86,8 \%$ em dietas para suínos aos $29,8 \mathrm{~kg}$ de peso vivo (PV) e de O'Connell et al. (2005), que relataram $88,5 \%$ para o CDMS do trigo em dietas para suínos com $80 \mathrm{~kg} / \mathrm{PV}$.

As maiores médias para os coeficientes obtidos com animais de maior peso podem estar relacionados à maturidade fisiológica do trato digestório e sugerem que a utilização do grão de 
trigo a partir de $45 \mathrm{~kg}$ de PV é mais eficiente para maximizar o potencial nutritivo. Os valores médios de energia digestível e metabolizável de 3,46 e 3,33 e de 3,39 e 3,31 Mcal/kg de MN, respectivamente para o trigo convencional e agroecológico foram próximos aos obtidos por Rostagno et al. (2011) de 3,35 e 3,26 Mcal/kg de ED e EM, respectivamente, para o trigo grão.

Quando comparado ao milho o trigo apresentou teores próximos de energia digestível e metabolizável, Santos et al. (2005), e Rostagno et al. (2011), encontraram valores para ED e EM do milho de 3,48 e 3,32; 3,46 e 3,34 Mcal/Kg de ED e EM na $\mathrm{MN}$, respectivamente.

Em comparação à outros alimentos, considerados alternativos, o trigo do presente estudo, independente do sistema de produção, apresentou valores superiores de ED e EM (Tabela 5) em relação, por exemplo, a casca de soja de 2,68 e 2,51 Mcal/kg de ED e EM (QUADROS et al., 2007), ao milheto de 3,02 e 2,93 Mcal/kg de ED e EM (BASTOS et al., 2005), farelo de arroz de 3,18 e 3,11 Mcal/kg de ED e EM, (ROSTAGNO et al., 2011), ao farelo de girassol de 2, 17 e 2,04 de ED e EM Mcal/kg (SILVA et al., 2002), o que indica o potencial do alimento como alternativa na nutrição de suínos.

\section{Conclusões}

Os sistemas de produção agroecológico e convencional não alteraram os coeficientes de digestibilidade do trigo. Os valores de energia digestível foram de 3,25; 3,56 e 3,59 Mcal/kg para o trigo convencional e 3,14; 3,45 e 3,57 Mcal $/ \mathrm{kg}$ para o trigo agroecológico, para as fases de 15, 45 e 75 $\mathrm{kg}$ de PV, respectivamente. A utilização do trigo a partir da fase de $45 \mathrm{~kg}$ apresentou melhores valores de digestibilidade, independente do sistema de produção.

\section{Agradecimentos}

Ao Conselho Nacional de Desenvolvimento Científico e Tecnológico (CNPq) pela concessão e apoio financeiro para o desenvolvimento das atividades, conforme processo 562650/2010-5/ REPENSA/CNPq;

À coordenação e funcionários da Escola Básica Municipal Agropecuária Demétrio Baldissarelli;

Ao CETREC/EPAGRI, Chapecó-SC, pela disponibilização do espaço; à VITAMIX nutrição animal pela doação dos suplementos e à AJINOMOTO pela doação dos aminoácidos industriais e realização de parte das análises laboratoriais.

\section{Referencias}

AGÊNCIANACIONALDEVIGILÂNCIASANITÁRIA - ANVISA. Resolução $N^{o} 7$, de 18 de fevereiro de 2011. Dispõe sobre limites máximos tolerados (LMT) para micotoxinas em alimentos. Brasília: BVS Ministério da Saúde, 2011. Disponível em: <http://bvsms.saude.gov.br/ bvs/saudelegis/anvisa/2011/ res0007_18_02_2011_rep. html>. Acesso em: 20 dez. 2012.

ASSOCIATION OF OFFICIAL ANALYTICAL CHEMISTRY - AOAC. Official methods of analysis. 12 ed. Washington: Association of Analytical Chemists, 1995. $1094 \mathrm{p}$.

BASTOS, A. O.; MOREIRA, I.; FURLAN, A. C.; FRAGA, A. L.; OLIVEIRA, R. P.; OLIVEIRA, E. Composição química, digestibilidade dos nutrientes e da energia de diferentes milhetos (Pennisetum glaucum (L.) R. Brown) em Suínos. Revista Brasileira de Zootecnia, Viçosa, v. 34, n. 2, p. 520-528, 2005.

BRASIL. Ministério da Agricultura e Abastecimento. Sindicato Nacional da Indústria de Alimentação Animal. Associação Nacional dos Fabricantes de Rações. Compêndio brasileiro de alimentação animal. São Paulo: ANFAR/CBNA/SDR, 2005. 204 p.

BRITO, M. S.; OLIVEIRA, C. F. S.; SILVA, T. R. G.; LIMA, R. B.; MORAIS, S. N.; SILVA, J. H. V. Polissacarídeos não amiláceos na nutrição de monogástricos- Revisão. Acta Veterinaria Brasilica, Mossoró, v. 2, n. 4, p. 111-117, 2008.

CALORI-DOMINGUES, M. A.; ALMEIDA, R. R.; TOMIWAKA, M. M.; GALLO, C. R.; GLORIA, E. M.; DIAS, C. T. S. Ocorrência de desoxinivalenol em trigo nacional e importado utilizado no Brasil. Ciência e Tecnologia de Alimentos, Campinas, v. 27, n. 1, p. 181185, 2007. 
CHOCT, M. Non-starch polysaccharides: effect on nutritive value. In: MACNAB, J. M.; BOORMAN, K. N. (Ed.). Factors influencing nutritive value. [S.1]: CAB International, 2002. p. 221-235.

COMISSÃO DE QUÍMICA E FERTILIDADE DO SOLO - CQFSRS/SC. Manual de adubação e calagem para os Estados do Rio Grande do Sul e de Santa Catarina. 10. ed. Porto Alegre: SBCS - Núcleo Regional Sul/UFRGS, 2004. 400 p.

COMPANHIA NACIONAL DE ABASTECIMENTO - CONAB. Acompanhamento da safra brasileira. Safra 2012/2013. Brasília: COANB, 2013. 28 p.

DEL ALAMO, G. A.; VERSTEGEN, M. W. A.; DEN HARTOG, L. A.; AYALA, P. P.; VILLAMIDE, M. J. Effect of wheat cultivar and enzyme addition to broiler chicken diets on nutrient digestibility, performance, and apparent metabolizable energy content. Poultry Science, Champaign, v. 87, n. 4, p. 759-767, 2008.

DEL PONTE, E. M.; FERNANDES, J. M. C.; PIEROBOM, C. R.; BERGSTROM, G. C. Giberela do trigo - aspectos epidemiológicos e modelos de previsão. Fitopatologia Brasileira, Brasília, v. 29, n. 6, p. 587-605, 2004.

EMPRESA BRASILEIRA DE PESQUISA AGROPECUÁRIA - EMBRAPA. Centro Nacional de Pesquisa de Solos. Sistema brasileiro de classificação de solos. Rio de Janeiro: Embrapa, 1999. 412 p.

FREITAS, F. B.; ZANELLA, I.; CARVALHO, A. D.; RABER, M. R.; BRUM JUNIOR, B. S.; SOUZA, J. F.; FRANCO, S. S.; ROSA, A. P. Avaliação de complexo multienzimático com níveis de trigo para poedeiras na fase de recria. ARS Veterinária, Jaboticabal, v. 21, n. 1, p. 1-6, 2005.

GRIESHOP, C. M.; REESE, D. E.; FAHEY JÚNIOR, G. C. Nonstarch polysaccharides and oligosaccharides in swine nutrition. In: LEWIS, A. J.; SOUTHERM, L. L. (Ed.). Swine nutrition. 2. ed. Boca Raton, FL: CRC Press, 2001. p. 107-130.

HAUSCHILD, L.; LOVATTO, P. A.; LEHNEN, C. R.; CARVALHO, A. d'A.; ALEBRANTE, L. Utilização do triticale e de enzimas em dietas para suínos: digestibilidade e metabolismo. Arquivo Brasileiro de Medicina Veterinária e Zootecnia, Belo Horizonte, v. 60, n. 2, p. 470-476, 2008.

HENDERSON, S. M.; PERRY, R. L. Agricultural process engineering. New York: John Wiley and Sons, $1955.402 \mathrm{p}$.

LE GOFF, G.; VAN MILGEN, J.; NOBLET, J. Influence of dietary fiber on digestive utilization and rate of passage in growing pigs, finishing pigs and adult sows. Animal Science, Penicuik, v. 74, n. 3, p. 503-515, 2002.

MARQUES, B. M. F. P. P.; ROSA, G. B.; HAUSCHILD, L.; CARVALHO, A. d'A.; LOVATTO, P. A. Substituição de milho por sorgo baixo tanino em dietas para suínos: digestibilidade e metabolismo. Arquivo Brasileiro de Medicina Veterinária e Zootecnia, Belo Horizonte, v. 59, n. 3, p. 767-772, 2007.

MATTERSON, L. D.; POTTER, L. M.; STUTZ, M. W.; SINGSEN, E. P. The metabolizable energy of feed ingredients for chikens. Research Report, Connecticut, v. 7, n. 1, p. 3-11, 1965.

MAZZONCINI，M.; BELLONI，P.; RISALITI，R.; ANTICHI. D. Organic Vs conventional winter wheat quality and organoleptic bread test. In: QLIF CONGRESS IMPROVING SUSTAINABILITY IN ORGANIC AND LOW INPUT FOOD PRODUCTION SYSTEMS, 3., 2007, Germany. Proceedings... Germany: University of Hohenheim, 2007. p. 135-138.

NATIONAL RESEARCH COUNCIL - NRC. Nutrient requirements of swine. Washington: National Academic Press, 1998. 189 p.

NOBLET, J.; VAN MILGEN, J. Energy value of pig feeds: effect of pig body weight and energy evaluation system. Journal of Animal Science, Champaign, v. 82, n. 13, p. 229-238, 2004.

NUNES, R. V.; ROSTAGNO, H. S.; ALBINO, L. F. T.; GOMES, P. C.; TOLEDO, R. S. Composição bromatológica, energia metabolizável e equações de predição da energia do grão e de subprodutos do trigo para pintos de corte. Revista Brasileira de Zootecnia, Viçosa, v. 30, n. 3, p. 785-793, 2001.

NYACHOTI, C. M.; HOUSE, J. D.; SLOMINSK, B. A.; SEDDON, I. R. Energy and nutrient digestibilities in wheat dried distillers' grains with solubles fed to growing pigs. Journal of the Science of Food and Agriculture, Weinheim, v. 85, n. 15, p. 2581-2586, 2005.

O'CONNELL, J. M.; SWEENEY, T.; CALLAN, J. J.; O'DOHERTY, J. V. The effect of cereal type and exogenous enzyme supplementation in pig diets on nutrient digestibility, intestinal microflora, volatile fatty acid concentration and manure ammonia emissions from finisher pigs. Animal Science, Cambridge, v. 81, n. 3, p. 357-364, 2005.

OK, H. E.; CHOI, S. W.; CHANG, H. J.; CHUNG, M. S.; CHUN, H. S. Occurrence of five 8-ketotrichothecene mycotoxins in organically and conventionally produced cereals collected in Korea. Food Control, Surrey, v. 22, n. 10, p. 1647-1652, 2011. 
PEDERSEN, C.; BOERSMA, M. G.; STEIN, H. H. Energy and nutrient digestibility in nutridense corn and other cereal grains fed to growing pigs. Journal of Animal Science, Champaign, v. 85, n. 10, p. 2473-2483, 2007.

PEKAS, J. C. Versatible swine labotarory apparatus for physiologic and metabolic studies. Journal of Animal Science, Savoy, v. 27, n. 5, p. 1303-1306, 1968.

QUADROS, A. R. B.; MOREIRA, I.; PAIANO, D.; RIBEIRO, C. R.; SILVESTRIM, N.; FURLAN, A. C. Avaliação nutricional da casca de soja integral ou moída, ensilada ou não, para suínos em fase de crescimento. Acta Scientiarum, Maringá, v. 29, n. 1, p. 31-38, 2007.

ROSTAGNO, H. S.; ALBINO, L. F. T.; DONZELE, J. L.; GOMES, P. C.; OLIVEIRA, R. F.; LOPES, D. C.; FERREIRA, A. S.; BARRETO, S. L. T.; EUCLIDES, R. F. Tabelas brasileiras para aves e suinos: composição de alimentos e exigências nutricionais. 3. ed. Viçosa, MG: UFV, 2011. 252 p.

SAKOMURA, N. K.; ROSTAGNO, H. S. Métodos de pesquisa em nutrição de monogástricos. Jaboticabal: FUNEP, 2007. 283 p.

SANTOS, J.; SANDI, A. J.; MIELE, M.; MARTINS, F.; JACOBINA, A.; SOUZA, B. Índices dos custos de produção de suínos. Concórdia: EMBRAPA, 2013. Disponível em: <http://www.cnpsa.embrapa.br/cias/ index.php?option $=$ com_content $\&$ view $=$ article $\&$ id $=170>$. Acesso em: 03 maio 2013.

SANTOS, J. S.; OLIVEIRA, T. M; MARTINS, L. M.; HASHIMOTO, E. H.; BASSOI, M. C.; PIRES, J. L. F.; MIRANDA, M. Z.; GARCIA, S.; ITANO, E. N.; ONO, E. Y. S.; KAWAMURA, O.; HIROOKA, E. Y. Monitoramento e nível de ingestão de desoxinivalenol por trigo. Semina: Ciências Agrárias, Londrina, v. 32, n. 4, p. 1439-1450, $2011 \mathrm{a}$.

SANTOS, H. P.; FONTANELI, R. S.; CAIERÃO, E.; SPERA, S. T.; VARGAS, L. Desempenho agronômico de trigo cultivado para grãos e duplo propósito em sistemas de integração lavoura-pecuária. Pesquisa Agropecuária Brasileira, Brasília, v. 46, n. 10, p. 1206-1213, 2011 b.

SANTOS, Z. A. S.; FREITAS, R. T. F.; FIALHO, E. T.; RODRIGUES, P. B.; LIMA, J. A. F.; CARELLOS, D. C.; BRANCO, P.A.C.; CANTARELLI, V. S. Valor nutricional de alimentos para suínos determinado na Universidade Federal de Lavras. Ciência e Agrotecnologia, Lavras, v. 29, n. 1, p. 232-237, 2005.

SCHNEWEIS, I.; MEYER, K.; RITZMANN, M.; HOFFMANN, P.; DEMPFLE, L.; BAUER, J. Influence of organically or conventionally produced wheat on health, performance and mycotoxin residues in tissues and bile of growing pigs. Archives of Animal Nutrition, London, v. 59, n. 3, p. 155-163, 2005.

SILVA, A. A.; MARQUES, B. M. F. P. P.; HAUSCHILD, L.; GARCIA, G. G.; LOVATTO, P. A. Digestibilidade e balanços metabólicos da silagem de grãos úmidos de milho para suínos. Ciência Rural, Santa Maria, v. 35, n. 4, p. 877-882, 2005.

SILVA, D. J.; QUEIROZ, A. C. Análise de alimentos: métodos químicos e biológicos. 2. ed. Viçosa: UFV, 2002. $235 \mathrm{p}$.

SILVA, C. A.; PINHEIRO, J. W.; FONSECA, N. A. N.; CABRERA, L.; NOVO, V. C. C.; SILVA, M. A. A.; CANTERI, R. C.; HOSHI, E. H. Farelo de girassol na alimentação de suínos em crescimento e terminação: digestibilidade, desempenho e efeitos na qualidade de carcaça. Revista Brasileira de Zootecnia, Viçosa, v. 31, n. 2, p. 982-990, 2002.

TEDESCO, M. J.; GIANELLO, C.; BISSANI, C. A.; BOHNEN, H.; VOLKWEISS, S. J. Análises de solo, plantas e outros materiais. 2. ed. Porto Alegre: Departamento de Solos, UFRGS. 1995. 174 p. (Boletim Técnico de Solos, n. 5).

THACKER, P. A.; WIDYARATNE, G. P. Nutritional value of diets containing graded levels of wheat distillers grains with solubles fed to broiler chicks. Journal of the Science of Food and Agriculture, Weinheim, v. 87, n. 7, p. 1386-1390, 2007.

UNIVERSIDADE FEDERAL DE VIÇOSA - UFV. SAEG Sistema para análises estatísticas. Versão 9.1: Viçosa: Fundação Arthur Bernardes, UFV, 2007.

URYNEK, W.; BURACZEWSKA, L. Effect of dietary energy concentration and apparent ileal digestible lysine:metabolizable energy ratio on nitrogen balance and growth performance of young pigs. Journal of Animal Science, Champaign, v. 81, n. 5, p. 1227-1236, 2003.

WIDYARATNE, G. P.; ZIJLSTRA, R. T. Nutritional value of wheat and corn distiller's dried grain with solubles: digestibility and digestible contents of energy, amino acids and phosphorus, nutrient excretion and growth performance of grower-finisher pigs. Canadian Journal of Animal Science, Ottawa, v. 87, n. 1, p. 103114, 2007.

ZIJLSTRA, R. T.; DE LANGE, C. F. M.; PATIENCE, J. F. Nutritional value of wheat for growing pigs: chemical composition and digestible energy content. Canadian Journal of Animal Science, Ottawa, v. 79, n. 2, p. 187194, 1999. 